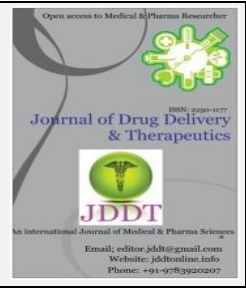

Open $\bigcirc$ Access

Research Article

\title{
Estimation of Nortriptyline hydrochloride in Bulk and Formulation by UV- Spectrophotometric Area Under Curve Method
}

\author{
Ms. Suchita R. Abhang*, Dr. Shankar M. Dhobale, Ms. Akshada D. Suryawanshi, Dr. Suresh L. Jadhav, Salim G. Patel \\ Vishal Institute of Pharmaceutical Education and Research Ale, Tal-Junnar, Dist-Pune (412411) Maharashtra, India
}

\begin{abstract}
The simple, precise and accurate UV-Spectrophotometric method has been developed and validated for the estimation of nortriptyline hydrochloride in bulk and dosage form. In that work was carried out for estimation of nortriptyline hydrochloride in bulk and pharmaceutical dosage form by utilizing area under curve (AUC) method. For this purpose the wavelength range 200-400nm was selected. DMSO was used as solvent throughout the work. Linearity was observed in concentration range $5-25 \mu \mathrm{g} / \mathrm{ml}\left(\mathrm{R}^{2}=0.996\right)$ for the method. The present method was found which can be used for routine quality control analysis for spectrophotometric estimation of Nortriptyline hydrochloride in bulk and dosage form.
\end{abstract}

Keywords: Nortriptyline hydrochloride, Area under curve (AUC), DMSO, UV-Spectrophotometric.

Article Info: Received 22 March 2019; $\quad$ Review Completed 24 April 2019; $\quad$ Accepted 01 May 2019; Available online 15 May 2019

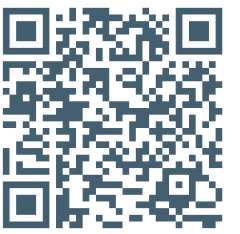

Cite this article as:

Abhang SR, Dr. Dhobale SM, Suryawanshi AD, Jadhav SL, Patel SG, Estimation of Nortriptyline hydrochloride in Bulk and Formulation by UV-Spectrophotometric Area Under Curve Method, Journal of Drug Delivery and Therapeutics. 2019; 9(3):147-150 http://dx.doi.org/10.22270/jddt.v9i3.2628

Ms. Suchita R. Abhang, Department of M.Q.A, Vishal Institute of Pharmaceutical Education and Research, Ale, Tal- Junnar, Dist- Pune (412411) Maharashtra, India.

\section{INTRODUCTION}

Nortriptyline hydrochloride is 3-(10, 11-Dihydro 5H-dibenzo [a, d] cyclohepten-5-ylidene propyl (methyl) amine hydrochloride were shown in Fig 1.

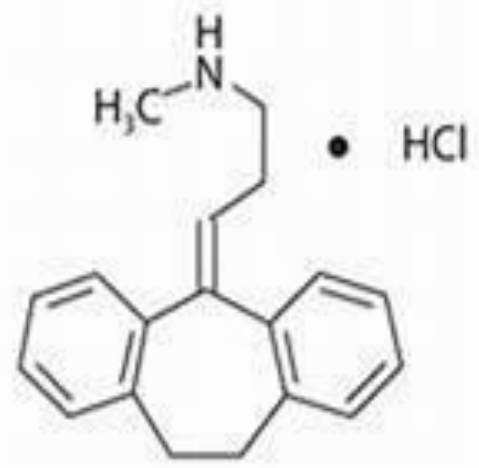

Figure 1: Chemical structure of Nortriptyline hydrochloride

Nortriptyline hydrochloride is an anti-depressant drug. It is a white or almost white powder and is sparingly soluble in water, sparingly soluble in ethanol (90\%) and in methylene chloride $^{1}$. Nortriptyline hydrochloride was block the reuptake of both nor adrenaline and serotonin into the pre synaptic terminals by binding to the transporters, viz. serotonin transporter (SERT) and norephidrin transporter (NET). The synaptic levels of this mono amine increased and there by prolong the action on the receptor. This Nortriptyline hydrochloride potentiates amine, neurotransmitter in the CNS 2, 3 Nortriptyline hydrochloride is the main active metabolite of Amitriptyline. It has been reported tohave a longer plasma half-life than Amitriptyline. Nortriptyline hydrochloride is subject to extensive first-pass metabolism in the liver to 10-hydroxy Nortriptyline, which is active. Extensive literature survey revealed that only UV spectroscopy 4-7 and PR-HPLC 8-10 methods were reported for the estimation of Nortriptyline hydrochloride in combination with other drug but there is no method was reported for the estimation of area under curve of Nortriptyline hydrochloride in bulk and in formulation by UVSpectrophotometry.

\section{MATERIALS AND METHODS}

1) Chemicals:

Nortriptyline hydrochloride standard drug substance was obtained as a gift sample from Alkem Laboratory, Mumbai. DMSO analytical reagent (AR) grade was used as solvent 
throughout the experimentation. A pharmaceutical preparation was purchased from local pharmacy.

\section{2) Instrumentation:}

A Shimadzu (Kyoto, Japan) model UV- 1800 double beam UVVisible spectrophotometer attached with computer operated software UV probe 2.33 with spectral width of $2 \mathrm{~nm}$, wavelength accuracy of $0.5 \mathrm{~nm}$ and pair of $1 \mathrm{~cm}$ matched quartz cells was used to measure absorbance of the resulting solutions. Analytical balance of make Mettler Toledo (Model JL 1503- C) was used for weighing purpose.

\section{3) UV-Spectroscopy Methods:}

\section{A) Area under curve method:}

The AUC (area under curve) method is applicable where there is no sharp peak or when broad spectra are obtained. It involves the calculation of integrated value of absorbance with respect to the wavelength between the two selected wavelengths $\lambda 1$ and $\lambda 2$. Area calculation processing item calculates the area bound by the curve and the horizontal axis. The horizontal axis is selected by entering the wavelength range over which area has to be calculated. This wavelength range is selected on the basis of repeated observation so as to get the linearity between area under curve and concentration. The above-mentioned spectrums were used to calculate AUC. ${ }^{11}$

\section{METHOD:}

\section{Experimental Work-}

\section{A) To check the solubility of Nortriptyline hydrochloride:}

$25 \mathrm{mg}$ of Nortriptyline hydrochloride was weighed and solubility of this sample was checked in $25 \mathrm{ml}$ distilled water, methanol, ethanol, DMSO.

\section{B) To identify the $\lambda$ max of Nortriptyline hydrochloride:}

Weigh $25 \mathrm{mg}$ of the pure drug was accurately weighed and dissolved small portion of DMSO and volume was made up to
$25 \mathrm{ml}$ using DMSO to give a standard stock solution of $1000 \mu \mathrm{g} / \mathrm{ml}$. Further $10 \mathrm{ml}$ of $1000 \mathrm{ppm}$ solution was withdraw and was diluted to $100 \mathrm{ml}$ of volumetric flask and 100 ppm solution is prepared by using distilled water. Suitable dilutions were made with distilled water to get standard solutions of concentration: $5,10,15,20$, $25 \mu \mathrm{g} / \mathrm{ml}$.[12] Spectrum peak details are shown in Figure 2 Spectrum peak pick.

\section{C) Sample preparation for analysis of tablet formulation:}

Sample solution was prepared from SENSIVAL 25. A sample equivalent to $25 \mathrm{mg}$ was weighed and was placed in $25 \mathrm{ml}$ volumetric flask; volume was made with solvent DMSO to get the concentration of $1000 \mu \mathrm{g} / \mathrm{ml}$. From this, $10 \mathrm{ml}$ transferred in $100 \mathrm{ml}$ of volumetric flask containing distilled water was diluent to form $100 \mu \mathrm{g} / \mathrm{ml}$ of stock solution further dilution of $5,10,15,20,25 \mathrm{ppm}$ and scanned in the range of $200-400 \mathrm{~nm}$ against distilled water + DMSO as blank $246.60 \mathrm{~nm}$ and then drug content was calculated by using standard calibration curve.

\section{D) Analytical Method Development and Validation:}

\section{Linearity:}

The linearity of an analytical procedure is the interval between the upper and lower concentration of analyte in the sample. For which demonstrated that the analytical procedure is of linearity. The standard solution of Nortriptyline hydrochloride $(5,10,15,20$, and $25 \mu \mathrm{m} / \mathrm{ml})$ was pipette out in a separated series of $25 \mathrm{ml}$ volumetric flask. Make up the volume with distilled water and mixed well. The absorbance maxima and area under curve for the solutions was measured at $246.60 \mathrm{~nm}$ and range of $200-400$ $\mathrm{nm}$ for two methods respectively against distilled water+DMSO as blank.

\section{RESULTS AND DISCUSSION:}

A) $\lambda$ max of Nortriptyline hydrochloride:

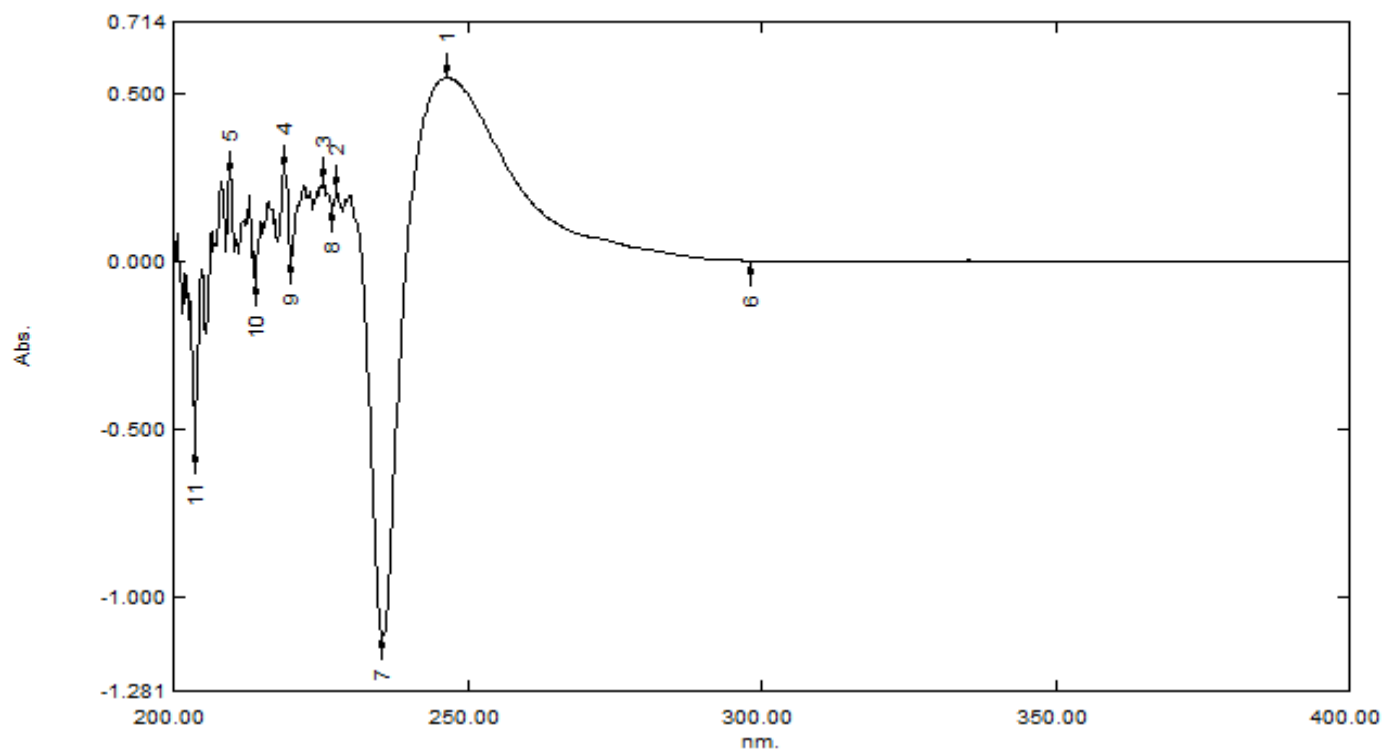

Figure 2: Spectrum Peak Report of Nortriptyline hydrochloride 


\section{B) Calibration Curve for Pure Drug:}

\section{a) Absorbance maxima method:}

Under the Experimental conditions described, the graph obtained for the absorbance maxima for pure drug showed linear relationship (Figure 3). Regression analysis was made for the slope, intercept and correlation coefficient values. The regression equations of calibration curve were $\mathrm{y}=$ $0.034 \mathrm{x}-0.0956\left(\mathrm{R}^{2}=0.9964\right)$ at $246.60 \mathrm{~nm}$ for absorption maxima the range was found to be $5-25 \mu \mathrm{m} / \mathrm{ml}$ for the UV spectrophotometric analysis.

Table 1: Calibration curve of Nortriptyline hydrochloride:

\begin{tabular}{|l|l|}
\hline CONC & ABS \\
\hline 5 & 0.063 \\
\hline 10 & 0.247 \\
\hline 15 & 0.425 \\
\hline 20 & 0.605 \\
\hline 25 & 0.735 \\
\hline
\end{tabular}

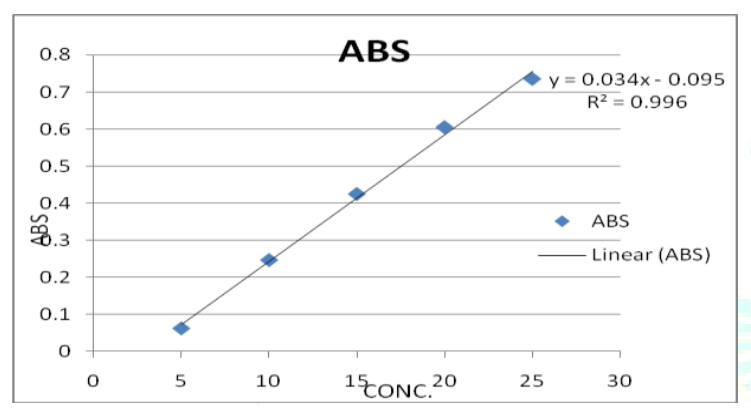

Figure 3: Calibration Curve of Nortriptyline hydrochloride (Pure drug)
Table 2: Calibration curve of SENSIVAL:

\begin{tabular}{|c|c|}
\hline CONC & ABS \\
\hline 5 & 0.018 \\
\hline 10 & 0.242 \\
\hline 15 & 0.470 \\
\hline 20 & 0.690 \\
\hline 25 & 0.921 \\
\hline
\end{tabular}

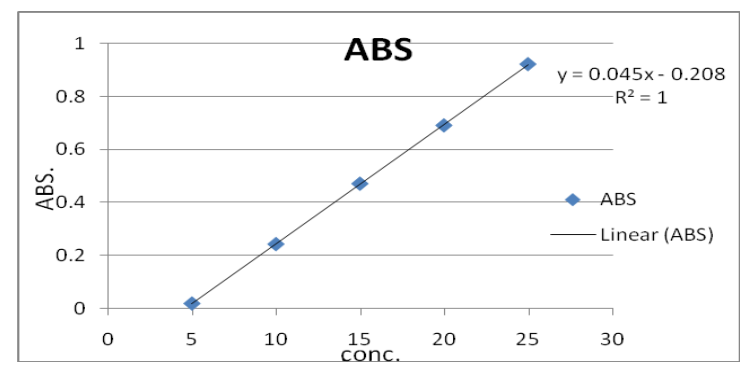

Figure 4: Calibration Curve of Nortriptyline hydrochloride (SENSIVOL)

\section{A) Area Under Curve Method :}

In the Experimental conditions described, the graph obtained for the Area Under Curve (AUC) spectra showed linear relationship (Figure3and 4). Regression analysis was made for the slope, intercept and correlation values. The range was found to be $5-25 \mu \mathrm{m} / \mathrm{ml}$ for the Area Under Curve UV-Spectrophotometric analysis.

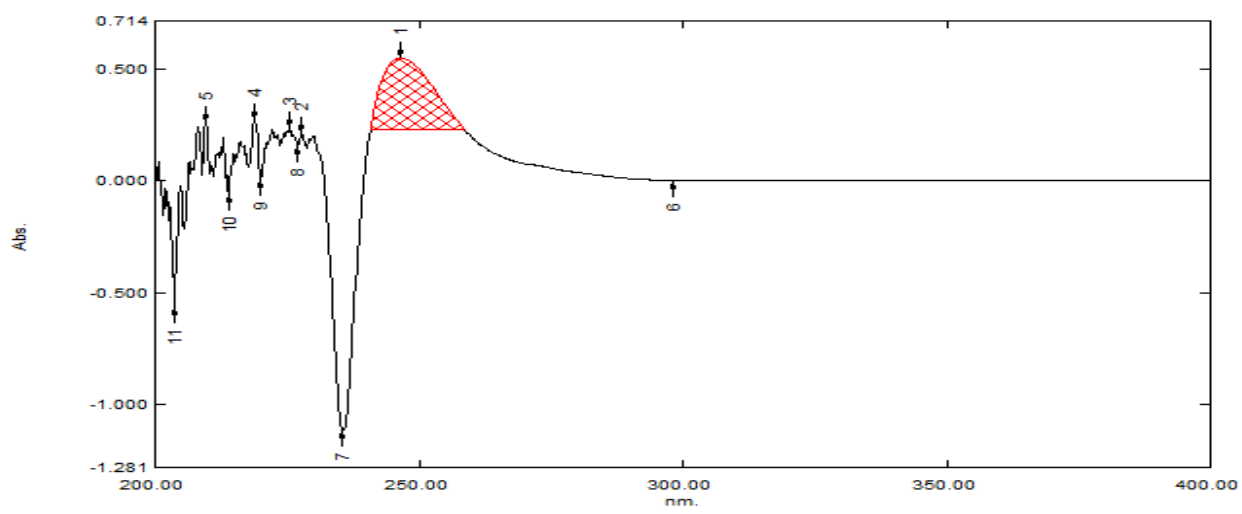

Figure 5: Area Under Curve of Nortriptyline hydrochloride (Pure drug)

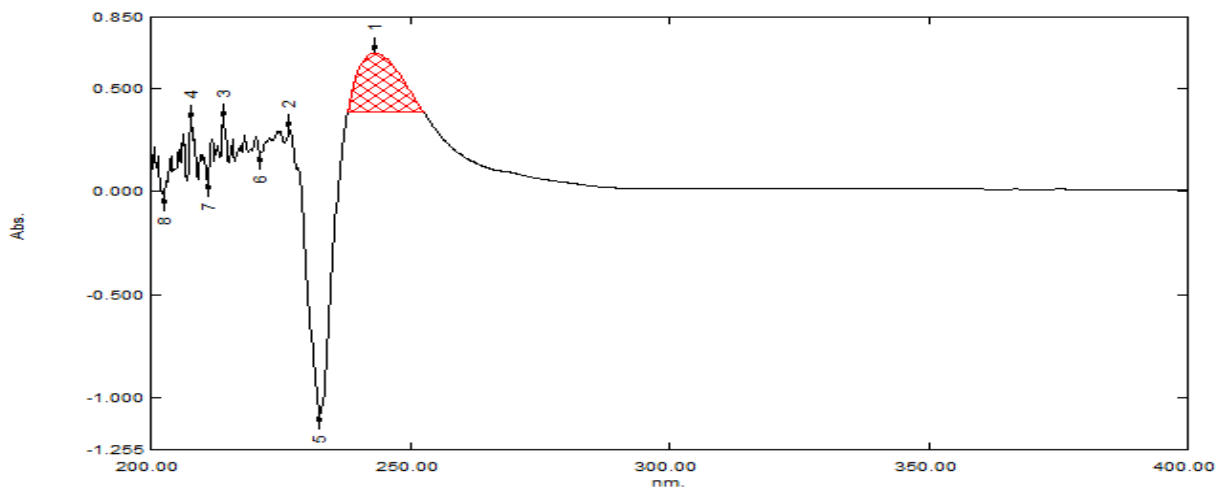

Figure 6: Area Under Curve of Nortriptyline hydrochloride (SENSIVOL). 


\section{CONCLUSION}

Simple UV spectrophotometric methods have been developed and validated for the determination of Nortriptyline hydrochloride bulk and formulation. Because of cost-effective and minimal maintenance, the present UV spectrophotometric methods can be preferred at small scale industries and successfully applied and suggested for the quantitative analysis of Nortriptyline hydrochloride in pharmaceutical formulations for QC, where economy and time are essential and to assure therapeutic efficacy.

\section{ACKNOWLEDGRMENT}

The authors are thankful acknowledge to Prof. Dhobale S.M. Head of MQA Department Vishal Institute of pharmaceutical education and research, Ale, Pune, for constant motivation and encouragement and also Alembic Pharmaceutical Ltd. for providing Nortriptyline hydrochloride standard drug sample. We would like to thank our principal Dr. Jadhav S. L. for providing us suitable environment for this work.

\section{REFERENCES}

1. The Indian Pharmacopoeia Volume I and II. The Controller of publication, New Delhi, 1996, 2014 7, A144-A145.

2. Alsion Brayfield, Martindale's the Complete Drugs Reference, $38^{\text {th }}$ edition, June 2014 444-445.

3. Merck Index. 1964, 6718 .

4. Moreno Ballesteros MP, Frutos P, Lasts JL, Castro D. Comparison of UV-Spectrophotometric and LC methods for the determination of Nortriptyline hydrochloride in polysorbate 80 based oil/ water microencapsulation. Indian Journal of pharmaceutical Research. 2000, 22(2):287-294.

5. Kulkarni AA, Satbhai A, Raut S, Kulkarni SD. UVSpectrophotometric estimation of Citalopram and Nortriptyline hydrochloride pharmaceutical dosage form. International Journal of Pharmacy \& Pharmaceutical Research. 2015; 4(4):104-111.
6. Safwan Ashourn, Nuha Kattaa. Simultaneous determination of Nortriptyline hydrochloride and Fluphenazine hydrochloride in microgram quantities from low dosage form by liquid chromatography-UV detection. Journal of Pharmaceutical Analysis, 2012, 438-443.

7. Patel Y, Patel MB, Patel NK. Development and Validation of Analytical UV method for simultaneous estimation of Gabapentine and Nortriptyline hydrochloride in pharmaceutical dosage form. Journal of pharmaceutical science \& Bio scientific research, 2015, 432-443.

8. Naveen Kumar M Sai, Malakondaiah D, Usha Sree G, Ajitha A. Development \& validation of stability indicating RP-HPLC method for simultaneous determination of Gabapentin and Nortriptyline hydrochloride in pharmaceutical dosage from. International Journal of pharmaceutical research \& analysis, 2015; 5(1):13-17.

9. Sreenivasulu BV, Sivaramakrishna V, Ramababu C. Development of validation of new RP-HPLC method for simultaneous determination of Nortriptyline hydrochloride and Gabapentin in combined dosage form. American Journal of pharmacy, 2015; 3(4):2321-3647.

10. Saravanan V, Revathi R, Meera N, Method Development and Validation for the Simultaneous Estimation of Lycopene and Ubidecarenone By RP-HPLC in Combined Pharmaceutical Dosage Form. Journal of Drug Delivery and Therapeutics, 2016; 6(5):46-51.

11. Chordiya Bhakti, Patel S G, Dhobale S M. Estimation of Pazufloxacin Mesylate in bulk and formulation by UVSpectrophotometric area under Curve Method, Int. Ref. J. of Science and Enginerring, 2018; A3:193-198

12. Pachpute Karishma and Jadhav S.L, Estimation of Disulfiram in Bulk and Formulation by UV- Spectrophotometric Area Under Curve method, Inventi Rpid:Pharma Analyis \& Quality Assurance, 2019; 2 [ ISSN 0976-3813]

13. Anandakumar K, Vanitha S, Development and Validation of UVSpectroscopic method for estimation of nortriptyline hydrochloride in bulk and in tablet dosage form,Int.J.Pharm and H.Care Res, 2018; 06(01):30-37. 